University of South Florida

DIGITAL COMMONS

Digital Commons @ University of

@ UNIVERSITY OF SOUTH FLORIDA

South Florida

$5-27-2014$

\title{
Self-Control Depletion and Nicotine Deprivation as Precipitants of Smoking Cessation Failure: A Human Laboratory Model
}

Bryan Heckman

University of South Florida, bryanheckman@gmail.com

Follow this and additional works at: https://digitalcommons.usf.edu/etd

Part of the Psychology Commons

\section{Scholar Commons Citation}

Heckman, Bryan, "Self-Control Depletion and Nicotine Deprivation as Precipitants of Smoking Cessation Failure: A Human Laboratory Model" (2014). USF Tampa Graduate Theses and Dissertations.

https://digitalcommons.usf.edu/etd/5235

This Dissertation is brought to you for free and open access by the USF Graduate Theses and Dissertations at Digital Commons @ University of South Florida. It has been accepted for inclusion in USF Tampa Graduate Theses and Dissertations by an authorized administrator of Digital Commons @ University of South Florida. For more information, please contact digitalcommons@usf.edu. 
Self-Control Depletion and Nicotine Deprivation as Precipitants of Smoking Cessation Failure:

A Human Laboratory Model

by

Bryan W. Heckman

A dissertation submitted in partial fulfillment

of the requirements for the degree of

Doctor of Philosophy in Clinical Psychology

Department of Psychology

College of Arts and Science

University of South Florida

Major Professor: Thomas H. Brandon, Ph.D.

David J. Drobes, Ph.D.

Mark S. Goldman, Ph.D.

Kristen Salomon, Ph.D.

Brent J. Small, Ph.D.

Date of Approval:

May 27, 2014

Keywords: self-control, smoking, behavioral economics, withdrawal, relapse

Copyright ( 2014, Bryan W. Heckman 


\section{Table of Contents}

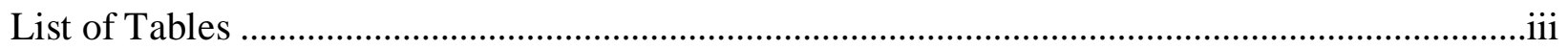

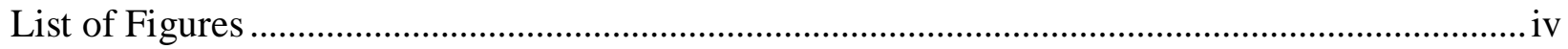

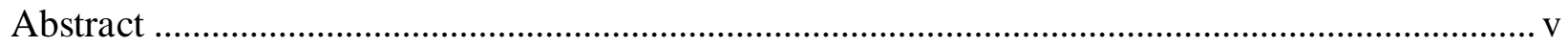

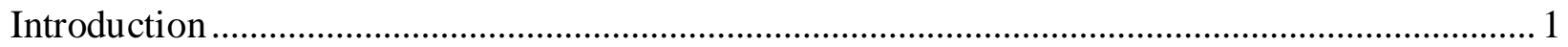

Self-Control Depletion as a Novel Precipitant to Cessation Failure....................................... 1

Nicotine Withdrawal, Craving, and Cessation Failure .......................................................... 3

Translational Paradigms to Detect Cessation Failure ......................................................... 4

Behavioral Economic Indices as Novel Mechanisms for Cessation Failure..........................6

Delayed Reward Discounting ................................................................................ 6

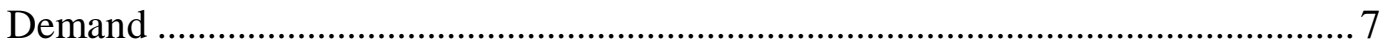

The Proposed Study ……………………....................................................................... 8

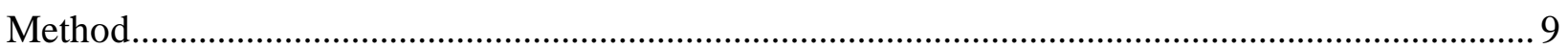

Experimental Design Overview …………………………………………………….. 9

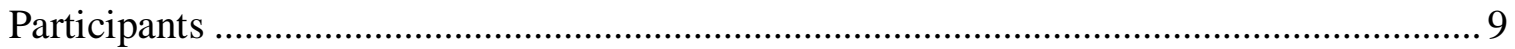

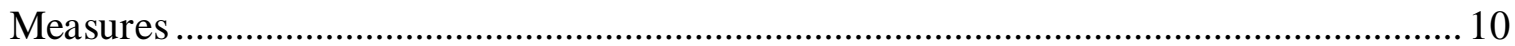

Participant Characteristics.......................................................................................... 10

Nicotine Deprivation Manipulation Check ………………........................................... 10

SCD Manipulation Check ……………………………..................................... 11

Craving ................................................................................................................. 11

Delayed Reward Discounting …………………………................................. 12

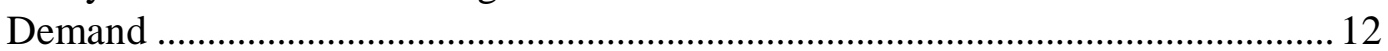

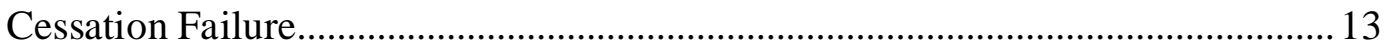

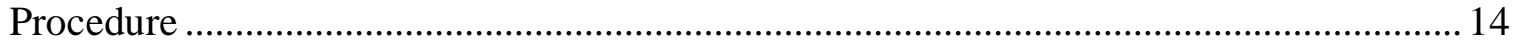

Nicotine Deprivation Manipulation...................................................................... 14

SCD Manipulation .................................................................................................. 15

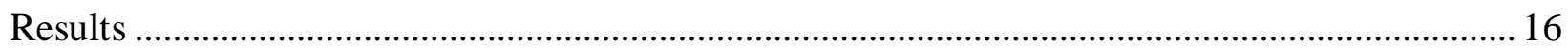

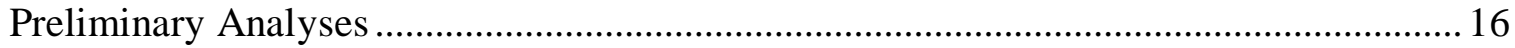

Participant Characteristics.................................................................................... 16

Nicotine Deprivation Manipulation Check ……………………………………...... 17

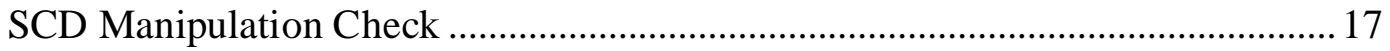

Primary Analyses ..................................................................................................... 18

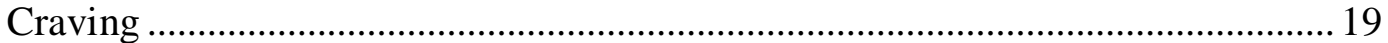

Delayed Reward Discounting …………………………..................................... 20 


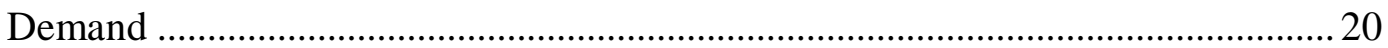

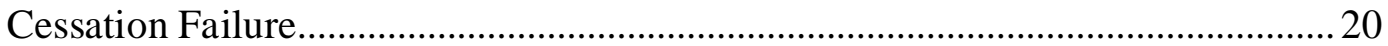

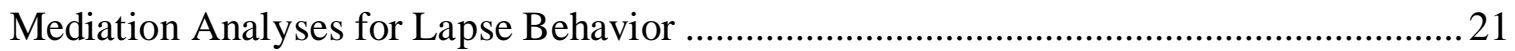

Nicotine Deprivation Mediation Model ............................................................. 22

SCD Moderated Mediation Model ......................................................................... 22

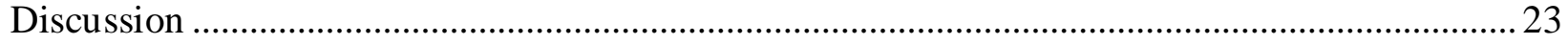

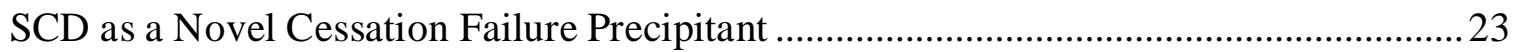

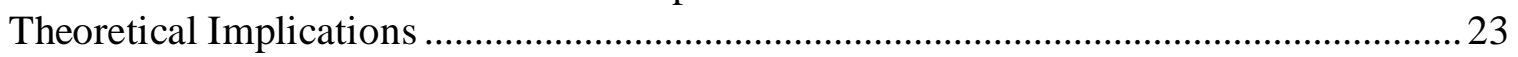

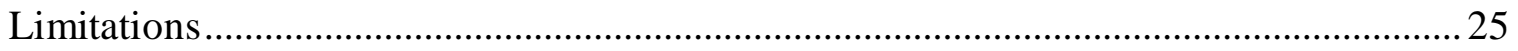

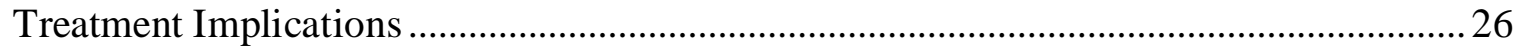

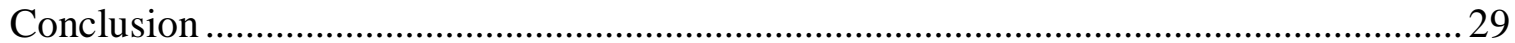

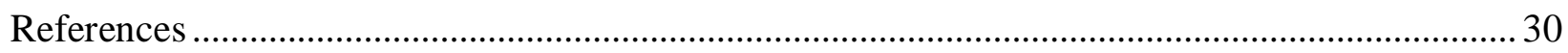




\section{List of Tables}

Table 1: Participant characteristics, with means (and SDs) or percentages.................................17

Table 2: Main and interaction effects for 2 X 2 ANCOVAs (craving, latency to smoke, and cigarette consumption) and MANCOVAs

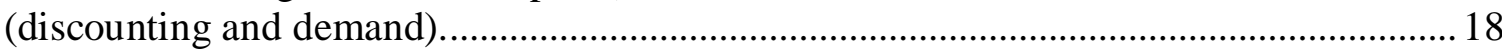




\section{List of Figures}

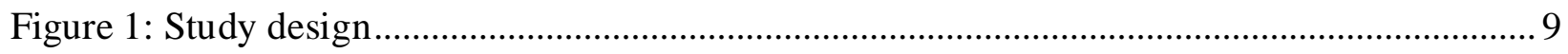

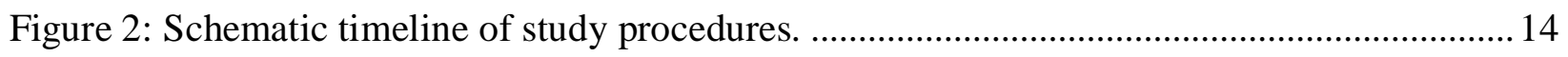

Figure 3: Mean composite craving ratings (and standard errors), as a function of the Self-Control Depletion manipulation x Nicotine Deprivation manipulation interaction $(\mathrm{p}=.04)$.

Figure 4: Latency to smoke (and standard errors), as a function of the Self-Control Depletion $(p=.04) \times$ Nicotine Deprivation manipulations $(p=.03)$. 


\begin{abstract}
The need to understand the reinforcing properties of smoking and potential precipitants of relapse is exemplified by evidence that relapse rates exceed 95\%. The Self-Control Strength model, which proposes that self-control is dependent upon limited resources and susceptible to fatigue, may offer insight into the relapse process. Indeed, there is empirical support that engaging in a task that requires self-control, relative to a comparable control, results in performance decrements on subsequent self-control tasks. The primary goal of the current study was to test whether self-control depletion (SCD) may serve as a novel antecedent for cessation failure, using a validated laboratory analogue of smoking lapse and relapse. We also aimed to compare SCD effects to those of a well-established relapse precipitant (i.e., nicotine deprivation), and test craving and behavioral economic indices as mechanisms for increased cessation failure. We used a 2 X 2 (12-hour deprivation vs. no deprivation; SCD vs. no SCD), crossed-factorial, between-subjects design ( $N=128$ smokers). Replicating prior research, nicotine deprivation significantly increased craving, cigarette demand, delay discounting, and lapse behavior. Furthermore, craving was the only mediator of deprivation effects on lapse behavior. Finally, the primary hypothesis of the study was supported, as SCD increased lapse behavior $(p=.04)$. Although no main effects were found for SCD on putative mediators (i.e., craving, demand, discounting), SCD was found to increase craving among nicotine deprived smokers $(p=.04)$, which mediated cessation failure. SCD appears to play in important role in smoking behavior and may be a viable candidate for intervention.
\end{abstract}




\section{Introduction}

Tobacco use is the leading preventable cause of mortality worldwide, causing over 5 million deaths per year (WHO, 2011). In the United States alone, smoking has caused approximately 20 million deaths over the past 50 years, and incurs at least \$289 billion in annual medical and other economic costs (USDHSS, 2014). Nevertheless, 18\% of adults in the United States continue to smoke (USDHSS, 2014), and 95\% of those who make a cessation attempt relapse within 1 year (CDCP, 2011). Fortunately, years of life lost can be reduced 90\% if cessation occurs by age 40 , and those who quit by age 60 can still mitigate this loss by $40 \%$ (USDHSS, 2014). Thus, there is a clear need to better understand what precedes cessation failure (i.e., relapse), and why, in order to identify targets for intervention development.

\section{Self-Control Depletion as a Novel Precipitant to Cessation Failure}

We previously proposed that state-dependent self-control resources may be central to the maintenance of nicotine dependence (Heckman, Ditre, \& Brandon, 2012). This suggestion was supported by experimental studies that found dependent smokers to be more likely to smoke a cigarette after resisting the consumption of delectable foods (Shmueli \& Prochaska, 2009, 2012), presumably due to the depletion of self-control resources needed to resist cravings to smoking (Hagger et al., 2013). Additionally, we found evidence that smoking can restore depleted selfcontrol resources (Heckman et al., 2012), suggesting a negative reinforcement pathway that may maintain nicotine dependence. Thus, self-control depletion (SCD) may serve as an interoceptive 
discriminative stimulus for smoking; however, the effects of SCD have never been tested on cessation failure directly.

In the aforementioned studies, SCD was conceptualized based on the Self-Control Strength Model (Baumeister, Bratslavsky, Muraven, \& Tice, 1998), which defines self-control as the conscious, deliberate, and effortful ability to manipulate one's own responses (Baumeister, Vohs, \& Tice, 2007). This theory also posits that self-control resources are limited and susceptible to fatigue, a supposition that has received strong empirical support as described in a meta-analysis of 198 experimental studies (Hagger, Wood, Stiff, \& Chatzisarantis, 2010). These studies demonstrate that engaging in an effortful task (e.g., emotional suppression, resisting temptations), relative to a comparable but benign task (e.g., acting naturally), results in performance decrements on a subsequent task that requires effort/self-control ( $d=.62$; typically indexed by persistence on a frustrating behavioral task).

Despite substantial evidence to support that SCD occurs, there is a lack of consensus for how this may occur. Initial evidence supported that blood glucose may serve as a biological proxy for self-control strength, as glucose levels decrease following effortful tasks, and glucose administration was found to restore depleted self-control. However, recent studies have questioned these findings, and suggest instead that SCD and its aftereffects are better explained through motivational processes (Beedie \& Lane, 2012; Inzlicht \& Schmeichel, 2013; Inzlicht, Schmeichel, \& Macrae, 2014; Kurzban, Duckworth, Kable, \& Myers, 2013; Molden et al., 2012; Robinson, Schmeichel, \& Inzlicht, 2010). It has been purported that SCD causes performance deficits because individuals shift priorities away from long term goals towards short term goals (Tice, Bratslavsky, \& Baumeister, 2001); however, this remains an empirical question (Christiansen, Cole, \& Field, 2012). 


\section{Nicotine Withdrawal, Craving, and Cessation Failure}

Early abstinence from nicotine may be a critical time period, given that the majority of smokers relapse within two weeks of initial cessation (Garvey, Bliss, Hitchcock, Heinold, \& Rosner, 1992; Kenford et al., 1994; Westman, Behm, Simel, \& Rose, 1997). Nicotine withdrawal is characterized by an aversive array of behavioral, affective, cognitive, and physiological symptoms that emerge as nicotine levels decrease (Hughes, 2007a, 2007b, 2007c; Shiffman, West, \& Gilbert, 2004). For the past 20 years, the diagnostic criteria for this withdrawal syndrome have been the concurrent experience of at least four symptoms: irritability, anxiety, restlessness, dysphoria/depressed mood, difficulty concentrating, increased appetite (or weight gain), sleep disturbance, or decreased heart rate (American Psychiatric Association, 1994). A strong evidence base also exists for cravings to smoke (Tiffany \& Wray, 2012), which is now recognized within the Diagnostic and Statistical Manual of Mental Disorders-V (American Psychiatric Association, 2013).

At an aggregate level, withdrawal effects are detectable within 30 minutes of abstinence (Hendricks, Ditre, Drobes, \& Brandon, 2006), typically peak within 1-2 weeks (Piasecki, Fiore, \& Baker, 1998), and typically remit within 3-4 weeks. However, considerable heterogeneity has been observed, both within and across individuals, in how these symptoms present and subside over time (Gilbert et al., 2002; Hughes, 1992; Piasecki, Jorenby, Smith, Fiore, \& Baker, 2003a; Shiffman \& Jarvik, 1976). Characterization of the complex and dynamic nature of nicotine withdrawal has enhanced our understanding of cessation failure, as cessation outcomes have been predicted via symptom severity, volatility, and trajectory (Hendricks, Delucchi, Benowitz, \& Hall, 2014; Kahler et al., 2002; Kenford et al., 2002; McCarthy, Piasecki, Fiore, \& Baker, 2006; Piasecki et al., 1998; Piasecki, Jorenby, Smith, Fiore, \& Baker, 2003b, 2003c; Piasecki et 
al., 2000; Strong et al., 2009). That reactivity to acute nicotine deprivation (i.e., withdrawal severity during initial quit day) has predictive utility suggests a timeframe that may facilitate the detection of those at risk for relapse.

Of the clinically recognized symptoms, the most robust effects of acute abstinence (e.g., 12 hours) appear to occur on negative affect (i.e., dysphoria, anxiety, irritability) and craving (Leventhal, Waters, Moolchan, Heishman, \& Pickworth, 2010). When all symptoms are tested independently, negative affect and craving have the strongest associations with relapse (Swan, Ward, \& Jack, 1996). Multi-predictor models that include all symptoms suggest that negative affect and craving contribute independently (Piper et al., 2011), and craving had the strongest predictive validity for cessation failure in the majority of studies of this type (Baker, Breslau, Covey, \& Shiffman, 2012; Etter \& Hughes, 2006; McCarthy et al., 2006; Piper et al., 2008; Strong et al., 2009; Swan et al., 1996).

\section{Translational Paradigms to Detect Cessation Failure}

Identification of lapse precipitants has been a critical first step for understanding cessation failure, given that $90 \%$ of those who have an initial lapse progress to continued smoking (Brandon, Tiffany, Obremski, \& Baker, 1990). The nicotine withdrawal literature illustrates the substantial time, effort, and expense required to identify important precipitants (e.g., craving), as this traditionally has occurred in the context of large-scale clinical trials. Antecedents have also been identified via retrospective self-report in cross-sectional designs (Shiffman, 1982; Shiffman, 1986), and prospectively within studies that used ecological momentary assessment (Shiffman, 2009), and geospatial mapping (Kirchner et al., 2013). Although all of these designs have strong external validity in that they examine long term behavioral outcomes, it is oftentimes difficult to infer causality given that antecedents are not 
manipulated directly. Thus, a vast evidence base must accumulate before a robust pattern can be observed conclusively.

To circumvent the aforementioned limitations, laboratory analogue paradigms of cessation failure have been developed to screen potential cessation pharmacotherapies, in an internally valid, timely, and cost-efficient manner (Lerman et al., 2007; McKee, 2009; McKee, Weinberger, Shi, Tetrault, \& Coppola, 2012; Perkins, Stitzer, \& Lerman, 2006; Perkins \& Lerman, 2014; Perkins et al., 2010; Perkins et al., 2013; Perkins et al., 2008). As such, these paradigms optimize the clinical utility of human laboratory research by facilitating the translation of basic to applied clinical research. These paradigms also offer methods for reverse translational research that tests treatment outcome findings within the laboratory setting (Roche et al., 2014). For example, McKee and colleagues (2009) have developed a cessation failure paradigm that captures lapse and relapse behaviors within a single experimental session, through the provision of financial incentives for abstinence. This paradigm has verified relapse antecedents commonly found in treatment outcome research, as increased lapse behavior has been observed following experimental manipulations of acute nicotine deprivation (1, 6, and 18 hours), negative affect, and alcohol consumption (Leeman, O’Malley, White, \& McKee, 2010; McKee, Krishnan-Sarin, Shi, Mase, \& O’Malley, 2006; McKee et al., 2010; McKee et al., 2012). That this cessation failure task can detect known predictors of relapse infers that it can also be used to identify novel relapse precipitants. Furthermore, the controlled setting in which the task is employed allows for the examination of mechanisms that may underlie the transition from abstinence to smoking (e.g., craving). That is, this laboratory analogue task can be utilized to test what may cause cessation failure, and why. 


\section{Behavioral Economic Indices as Novel Mechanisms for Cessation Failure}

Delayed Reward Discounting. Shift in reward preferences is an integral construct within behavioral economic theory, termed delayed reward discounting (Bickel, Koffarnus, Moody, \& Wilson, 2014). Discounting tasks have participants choose between a series of smaller immediate monetary rewards versus larger delayed monetary rewards, and responses are used to objectively quantify impulsive decision-making (Madden \& Bickel, 2009). As preferences for immediate rewards increase, the discounting rate becomes steeper (i.e., greater discounting), indicating higher levels of impulsivity. Discounting is often conceptualized as a stable individual difference variable, but is also susceptible to state fluctuations through variety of experimental manipulations (Koffarnus, Jarmolowicz, Mueller, \& Bickel, 2013). Therefore, discounting tasks may provide a method to test the assumption that SCD causes greater impulsive decisionmaking, as suggested by the Self-Control Strength Model.

The clinical relevance of delay discounting is readily apparent among smokers, who often choose the short-lived, immediate, rewards of drug use (e.g., pleasurable effects and/or withdrawal reversal) over larger delayed rewards of abstinence (e.g., health, social, and economic benefits). Indeed, a meta-analysis of 17 studies indicated that smokers have higher discounting rates than nonsmokers $(d=.57)$, across both clinical and subclinical samples (MacKillop et al., 2011). Within smokers, greater discounting is associated with nicotine dependence and predicts days to lapse (MacKillop \& Kahler, 2009). Furthermore, experimental manipulations of acute nicotine deprivation have been found to increase discounting (Ashare \& Hawk, 2012; Field, Santarcangelo, Sumnall, Goudie, \& Cole, 2006; Mitchell, 2004), suggesting that discounting may serve as a novel mechanism for cessation failure. 
Demand. Behavioral economists have also developed objective behavioral tasks that assess the relative reinforcement value of commodities, termed demand (Bickel, Jarmolowicz, Mueller, \& Gatchalian, 2011). Specific to substance use, purchase tasks quantify participants’ drug consumption across varying levels of cost (MacKillop et al., 2008; Murphy \& MacKillop, 2006; Murphy, MacKillop, Skidmore, \& Pederson, 2009; Murphy, MacKillop, Tidey, Brazil, \& Colby, 2011). These responses contribute to multidimensional demand indices of consumption, expenditure, and price sensitivity (MacKillop et al., 2009). Elevated cigarette demand is associated with higher levels of nicotine dependence (MacKillop et al., 2010; Murphy et al., 2011), and cessation failure (MacKillop \& Murphy, 2007). Additionally, cigarette demand is increased through experimental manipulation of acute nicotine deprivation (MacKillop et al., 2012). Thus, demand may serve as a novel motivational process that underlies cessation failure.

Conceptually, there appears to be overlap between the constructs of demand and craving, in that they index motivation to use a substance. However, demand may reflect motivational processes that occur outside subjective awareness, whereas self-reported craving is an entirely subjective experience. Thus, these constructs may serves as complementary assessment tools (Laibson, 2001), and indeed, each provide unique predictive validity (Acker \& MacKillop, 2013; MacKillop et al., 2012; MacKillop et al., 2010). Purchase tasks may be particularly helpful for the detection of SCD effects, which tend to influence behavioral but not self-report indices (Hagger et al., 2010). No relationship has been observed between SCD and craving across three studies of non-deprived smokers (Heckman et al., 2012; Shmueli \& Prochaska, 2009, 2012). However, no study has examined the influence of SCD on motivation to smoke as measured via demand indices, or during acute nicotine withdrawal. 


\section{The Proposed Study}

In summary, we have presented evidence that 1 ) acute nicotine deprivation is a wellestablished context that contributes to cessation failure, as indexed by real world treatment outcomes and analogue tasks; 2) deprivation manipulations cause increases in craving, demand, and discounting; 3) craving, demand, and discounting predict cessation failure (i.e., lapse/relapse), and 4) SCD may promote cessation failure. This suggests that behavioral economic constructs and craving offer clinically relevant pathways (i.e., the why) through which environmental constraints (i.e., the what) may influence smoking behavior. These constructs also offer avenues to test theory-driven pathways (i.e., impulsive decision-making, motivation) that may be influenced by SCD.

A 2 x 2 experimental design that tests an established (i.e., deprivation), and a novel (i.e., SCD), relapse precipitant on a cessation failure task provides an internally valid method to identify novel contextual factors that may precede relapse in the real world. An additional strength of this design is that the magnitude of the main effects for the relapse precipitants can be compared, and their interaction examined. The current study is the first to apply this laboratory model to examine SCD as a novel contributor to cessation failure.

Specifically, we tested the hypotheses that SCD and nicotine deprivation conditions would show elevated craving, demand, discounting, and cessation failure (i.e., decreased latency to smoke and increased cigarette consumption), when compared to their control conditions. We also hypothesized these manipulations would interact synergistically, such that those deprived and depleted would evince the greatest effect upon these measures, relative to the remaining three conditions. Finally, we hypothesized that craving, demand, and discounting would mediate cessation failure. 


\section{Method}

\section{Experimental Design Overview}

As depicted in Figure 1, participants were randomly assigned to one of four conditions, stratified by gender, in this 2 X 2 crossed factorial between-subjects design.

Self-Control Depletion

(Emotional Suppression)

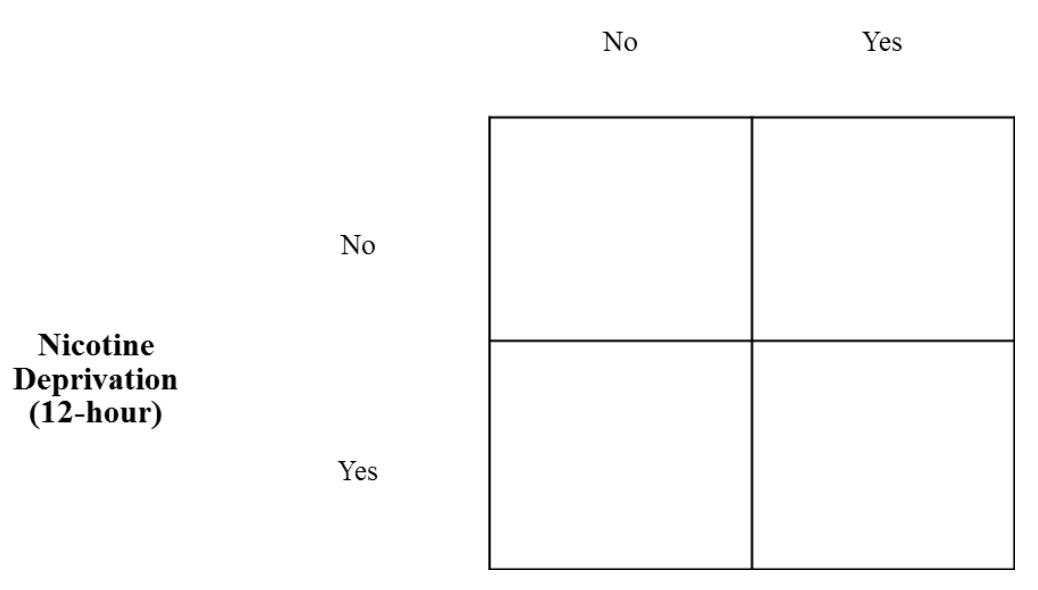

Figure 1. Study design.

\section{Participants}

This study was powered at .80 to detect 'medium' sized main and interaction effects, with a two-tailed alpha level of .05 (Cohen, 1988). Participants were recruited from the Tampa, Florida area, via newspaper and electronic advertisements. Prospective participants were screened via telephone for the following inclusion criteria: English-speaking, 18-65 years of age, smoked at least 15 cigarettes per day, and smoked at this rate for at least one year. Prospective 
participants were also screened for the following exclusion criteria: concurrent use of other nicotine or tobacco products, actively attempting to quit smoking, pregnant, and hearing or visual impairment that would interfere with study procedures. Of the 164 participants who met telephone screening criteria, one per condition (i.e., four) were excluded at the experimental session due to other tobacco/nicotine use or active cessation attempt. Twenty eight participants randomized to the deprivation conditions and four participants assigned to the non-deprived conditions were excluded due to failure to meet pre-session expired carbon monoxide (CO) concentration levels (see below).

\section{Measures}

Participant Characteristics. Demographic and smoking history information was collected at baseline. This included the Fagerström Test for Nicotine Dependence (Heatherton, Kozlowski, Frecker, \& Fagerstrom, 1991), Contemplation Ladder (Biener \& Abrams, 1991), and an index of cessation self-efficacy that aggregated confidence in the ability to quit smoking for a week, month, and year $(\alpha=.79)$. As part of a secondary study, we also administered baseline assessments of self-reported pain (Von Korff, 2011), trait impulsivity (Whiteside \& Lynam, 2001), and impression management (Paulhus, 1991).

Nicotine Deprivation Manipulation Check. Compliance with the deprivation manipulation instructions was verified via self-reported nicotine abstinence and pre-session expired carbon monoxide (CO) concentration levels. Participants randomized to the deprivation conditions were required to have a CO of $\leq 11 \mathrm{ppm}$ (Leventhal et al., 2010), and those nondeprived were required to have a CO level greater than 11ppm. Additionally, participants completed the 9-item version of the Minnesota Nicotine Withdrawal Scale (Hughes \& Hatsukami, 1986), which yielded a reliable total withdrawal score $(\alpha=.82)$. 
SCD Manipulation Check. The degree to which participants followed the assigned SCD instruction set was assessed with a 3-item $(\alpha=.82)$ emotional suppression index (Gross, 1998; Heckman et al., 2012). Subjective cognitive depletion was assessed with a 3-item $(\alpha=.76)$ composite index of how effortful, difficult, and fatiguing it was to follow the instruction set (Baumeister et al., 1998; Heckman et al., 2012). Emotional suppression and cognitive depletion scores were on a 7-point Likert scale, with possible scores of zero to six. We also assessed positive and negative affect via the Mood Form (Diener \& Emmons, 1984), before and after the manipulation ( $\alpha$ 's $>$.86). Finally, we examined glucose utilization as a biological proxy for selfcontrol strength (Gailliot et al., 2007). This was defined as the change in glucose levels from baseline to post-depletion, with greater decreases indicative of greater SCD as found in a metaanalysis of five prior studies ( $d=-.87$; Hagger et al., 2010). A digitized Aviva glucose meter, disposable lancing device, and a disposable test strip, were used to tested glucose levels (mg/dL). To allow pre-session glucose levels to stabilize (i.e., reduce error variance), all participants were asked to abstain from eating for 2 hours before their appointment time (Gailliot et al., 2007).

Craving. We used a composite craving score that was not subject to ceiling effects commonly observed in heavy smokers following nicotine deprivation, and that took into account expected baseline differences between deprivation conditions (Sayers \& Sayette, 2013; Sayette, Martin, Hull, Wertz, \& Perrott, 2003; Sayette, Martin, Wertz, Shiffman, \& Perrott, 2001). Composite craving was calculated by multiplying baseline craving ratings on the Tobacco Craving Questionnaire-Short Form (Heishman, Singleton, \& Pickworth, 2008) with proportion of change as measured by a Magnitude Estimation of Urge score completed after the SCD manipulation (Sayette et al., 2001). The magnitude estimate measure asked participants to compare their current urge to smoke, relative to their baseline urge (arbitrarily assigned a value 
of 10). Thus, the composite craving index accounts for 1) initial craving and 2) increases in craving from the SCD. Sayette and colleagues (2001) have used composite scores to examine acute responses to smoking-specific cues among deprived, and non-deprived, smokers.

Delayed Reward Discounting. The Monetary Choice Questionnaire is a validated assessment of discounting (Kirby, Petry, \& Bickel, 1999). Participants made 27 choices between smaller rewards available immediately and larger rewards available after a delayed period of time. These reward choices are preconfigured at various levels of hyperbolic discounting, and participants' choices yield temporal discounting estimates $(k)$ of reward at three levels of reward magnitude (small: \$25-\$35; medium: \$50-\$60; large: \$75-\$85). Although all reward choices were hypothetical, this task has convergent validity with choices that are actualized (Lagorio \& Madden, 2005; Madden, Begotka, Raiff, \& Kastern, 2003; Madden et al., 2004).

Prior to analyses reported below, temporal discounting values $(k)$ were approximately normalized using the natural-log transformation. However, to aid interpretation we report untransformed means and standard errors (Acker \& MacKillop, 2013).

Demand. Demand was assessed with a state version of the Cigarette Purchase Task (MacKillop et al., 2008; Murphy et al., 2011), which asked participants to indicate how many cigarettes they would consume right now. Responses across 21 price intervals (\$0-\$5) were used to generate five demand indices, including: intensity (cigarette consumption at the lowest price), breakpoint (first price at which cigarette consumption is zero), Pmax (price at which expenditure is maximized), Omax (maximum financial expenditure on cigarettes), and elasticity of demand (sensitivity of cigarette consumption to increases in cost). We administered a practice purchase task (on pizza) at baseline to familiarize participants with the task. 
Cigarette purchase task data were first screened for low effort responding, defined as more than two contradictions at escalating prices or invariant responses (Acker \& MacKillop, 2013). Low effort responding was observed for five participants. Similar results were observed when demand analyses were conducted with these participants excluded, and when their data were mean imputed, and we report the latter below. Data were examined for distribution abnormalities and outliers, defined as $z>3.29$ (i.e., $p<.001$, two-tailed test), and those identified were recoded as one unit above the next highest non-outlier at the second decimal (Tabachnick \& Fidell, 2013). With the exception of elasticity, demand indices were generated using an observed values approach (Murphy \& MacKillop, 2006). Elasticity was derived through exponential demand curve modeling (Hursh \& Silberberg, 2008), which was conducted within Graphpad Prism $(k=3)$. Good fit to the data was observed for the overall mean values $\left(R^{2}=.84\right.$ $98)$ and individual values $\left(R^{2}=.72-75\right)$.

Cessation Failure. The cessation failure laboratory analogue task was comprised of a 1) delay and 2) self-administration period (McKee, 2009). At the beginning of the delay period, a tray containing eight preferred brand cigarettes, an ashtray, and a lighter were presented to participants, with instructions that they could begin smoking at any point over the next 50 minutes. They were also informed that they could earn $\$ 1$ for every 5 minutes that they delayed smoking, with a maximum payment of $\$ 10$ over the 50 minute period. The 60 minute smoking self-administration period was initiated when a decision to smoke was made, or after the 50 minute delay period had expired. During this ad libitum smoking period, participants were instructed to "smoke as little or as much as you wish.” The primary dependent variables were latency to smoke (i.e., lapse) and the number of cigarettes smokes (i.e., relapse). 
Participants were informed that the duration of the experimental session would be the maximum potential time to complete the cessation failure task (i.e., 110 minutes), regardless of performance on the delay period. However, five participants chose to forego the task to leave the experimental session early and were excluded from the latency to smoke analyses. Three additional participants chose to terminate the experimental session during the ad lib portion and were excluded from cigarette consumption analyses.

\section{Procedure}

The experimental session involved obtaining informed consent and HIPAA authorization, collection of baseline measures, the SCD manipulation, collection of post-depletion measures (e.g., craving, discounting, and demand), and the cessation failure task. The average duration of each component is depicted in Figure 2. Participants were compensated at least \$45, with the potential to earn up to $\$ 10$ more based the cessation failure task. All procedures were approved by the Institutional Review Board at the University of South Florida.

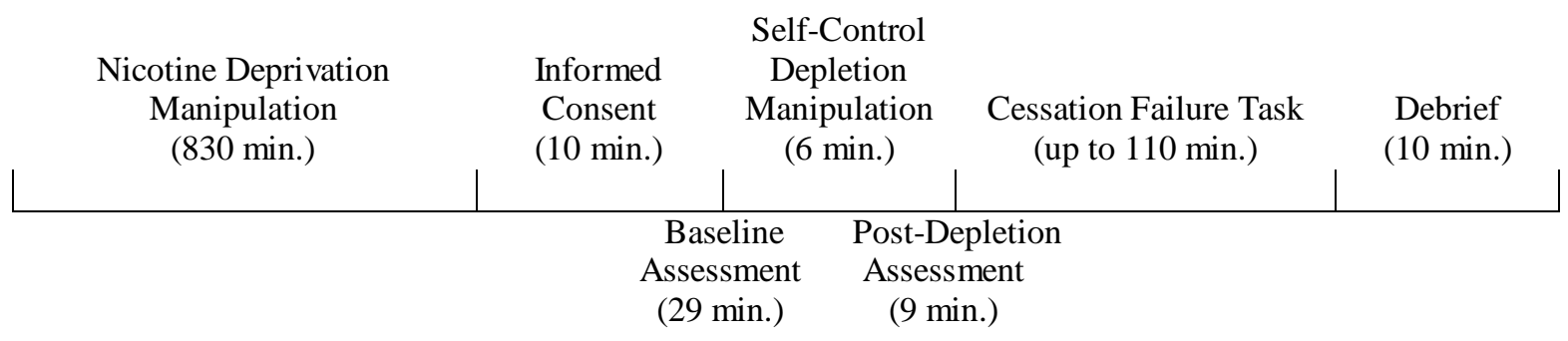

Figure 2. Schematic timeline of study procedures.

Nicotine Deprivation Manipulation. Those randomized to the deprivation conditions were instructed to abstain from using any nicotine containing products for 12 hours prior to their laboratory session. Non-deprived participants were instructed to smoke one cigarette exactly 5 minutes prior to their appointment to standardize pre-session smoking. 
SCD Manipulation. All participants watched the same six minute emotionally evocative video clip depicting mutations and death of sea life (Baumeister et al., 1998; Heckman et al., 2012), and were informed that they would be video-recorded while viewing the clip. Those in the SCD conditions were instructed to: "Remain completely neutral on the inside and out. Please try your best not to let any feelings or responses you may have show on your face, and to the best of your ability, try to keep all of your internal reactions suppressed.” Participants in the no SCD conditions were instructed: “Be as natural as possible, both on the inside and out. If you have any feelings or reactions to the movie, let them flow naturally.” 


\section{Results}

\section{Preliminary Analyses}

Participant Characteristics. As depicted in Table 1, the final sample $(N=128)$ was $51 \%$ female with a mean age of $36.48(S D=12.04)$ years. The majority of participants were Caucasian (75\%), with 20\% identifying as African American, 2\% as American Indian or Alaskan Native, 2\% Native Hawaiian or other Pacific Islander, and 1\% as Asian; and 11\% were Hispanic or Latino. Only 6\% had obtained a college degree, and 38\% had household income greater than $\$ 20,000$. Participants smoked $20.40(S D=6.86)$ cigarettes per day and were moderately to highly dependent on tobacco (0-10 scale; $M=5.69 ; S D=1.87)$. Participants indicated moderate interest in quitting smoking (0-10 scale; $M=4.66$; $S D=2.59)$, but minimal self-efficacy to do so $(0-4$ scale; $M=.90 ; S D=1.02)$.

Analyses of variances (ANOVAs) and Chi-square analyses were used to verify that randomization led to equivalent group characteristics, and as expected no significant differences were found across the experimental conditions for the majority of baseline characteristics. However, those in the deprivation condition were less nicotine dependent $[(M=5.36 ; S D=1.85)$ vs. $(M=6.02 ; S D=1.84), F(1,124)=4.02, p=.047$, partial $\eta^{2}=.03$ ], and had greater selfefficacy $\left[(M=1.13 ; S D=1.20)\right.$ vs. $(M=.66 ; S D=.74), F(1,124)=7.10, p=.01$, partial $\eta^{2}=$ .05)]. As such, they were included as covariates in subsequent analyses. All analyses were conducted with SPSS v21, with traditional significance levels set at $p<.05$ (two-tailed). 
Table 1. Participant characteristics, with means (and SDs) or percentages.

\begin{tabular}{|c|c|c|c|c|c|}
\hline & $\begin{array}{c}\text { No Self-Control } \\
\text { Depletion }+ \\
\text { No Nicotine } \\
\text { Deprivation } \\
(n=32) \\
\end{array}$ & $\begin{array}{c}\text { Self-Control } \\
\text { Depletion + } \\
\text { No Nicotine } \\
\text { Deprivation } \\
(n=32) \\
\end{array}$ & $\begin{array}{c}\text { No Self-Control } \\
\text { Depletion + } \\
\text { Nicotine } \\
\text { Deprivation } \\
(n=32) \\
\end{array}$ & $\begin{array}{c}\text { Self-Control } \\
\text { Depletion + } \\
\text { Nicotine } \\
\text { Deprivation } \\
(n=32) \\
\end{array}$ & $\begin{array}{c}\text { Total } \\
(N=128)\end{array}$ \\
\hline \multicolumn{6}{|l|}{ Demographics } \\
\hline Age & 38.94 (12.39) & 38.16 (12.56) & 33.72 (11.90) & 35.09 (11.05) & 36.48 (12.04) \\
\hline $\begin{array}{l}\text { Gender } \\
\text { (\% Female) }\end{array}$ & $50 \%$ & $50 \%$ & $50 \%$ & $53 \%$ & $51 \%$ \\
\hline $\begin{array}{l}\text { Race } \\
\text { (\% Caucasian) }\end{array}$ & $78 \%$ & $84 \%$ & $78 \%$ & $59 \%$ & $75 \%$ \\
\hline $\begin{array}{l}\text { Ethnicity } \\
\text { (\% Hispanic) }\end{array}$ & $9 \%$ & $9 \%$ & $16 \%$ & $9 \%$ & $11 \%$ \\
\hline $\begin{array}{l}\text { Education } \\
\text { (\% College degree) }\end{array}$ & $13 \%$ & $0 \%$ & $6 \%$ & $3 \%$ & $6 \%$ \\
\hline $\begin{array}{l}\text { Income } \\
(\%>\$ 20,000)\end{array}$ & $38 \%$ & $38 \%$ & $34 \%$ & $41 \%$ & $38 \%$ \\
\hline \multicolumn{6}{|l|}{ Smoking History } \\
\hline Cigarettes per day & 20.33 (5.05) & 21.41 (6.29) & 19.91 (5.88) & 19.97 (9.58) & $20.40(6.86)$ \\
\hline FTND* & $5.78(1.81)$ & 6.25 (1.87) & 5.50 (1.88) & $5.22(1.84)$ & 5.69 (1.87) \\
\hline CL & $5.34(2.56)$ & $4.44(2.33)$ & $4.66(2.89)$ & $4.22(2.52)$ & $4.66(2.89)$ \\
\hline Self-efficacy* & $.58(.81)$ & $.74(.65)$ & $.98(1.20)$ & $1.28(1.20)$ & $.90(1.02)$ \\
\hline
\end{tabular}

Nicotine Deprivation Manipulation Check. As expected, those in the nicotine deprivation conditions had lower CO levels $(M=5.49$; $S E=1.88)$, relative to the satiated groups $(M=38.82 ; S E=1.88), F(1,122)=152.98, p<.001$, partial $\eta^{2}=.56$. Nicotine deprived participants also had higher self-reported nicotine withdrawal $(M=2.36$; $S E=.11)$, compared to those non-deprived $(M=1.85 ; S E=.11), F(1,122)=11.20, p=.001$, partial $\eta^{2}=.08$.

SCD Manipulation Check. Those randomized to SCD conditions reported engaging in higher levels of emotional suppression $(M=4.44$; $S E=.15)$, compared to those in the no SCD conditions $(M=1.13 ; S E=.15), F(1,122)=234.76, p<.001$, partial $\eta^{2}=.66$. The SCD conditions $(M=1.78 ; S E=.16)$ also reported that following the assigned instruction set led to more cognitive depletion compared to those asked to act naturally $(M=.60 ; S E=.16), F(1,122)$ 
$=28.52, p<.001$, partial $\eta^{2}=.19$. No differences were observed for negative affect $(p=.38)$ or positive affect ( $p=.70)$. With respect to glucose utilization, only 59\% complied with the presession dietary restriction instructions, which may have precluded the ability to detect depletion effects within the full sample (Depleted: $M=-2.74 ; S E=1.07$; Non-Depleted: $M=-1.90$; $S E=$ $1.08 ; p=.56)$. The subsample that complied with the two hour dietary restriction showed the expected pattern of greater glucose utilization (i.e., decreased blood glucose levels after the SCD manipulation $)$ in the SCD condition $(M=-2.54$; $S E=1.25)$, relative to no SCD participants $(M=$ $.85 ; S E=1.39$ ), which approached traditional levels of statistical significance despite reduced power, $F(1,70)=3.22, p=.08$, partial $\eta^{2}=.04$.

\section{Primary Analyses}

Table 2 provides an overview of results for the primary analyses.

Table 2. Main and interaction effects for 2 X 2 ANCOVAs (craving, latency to smoke, and cigarette consumption) and MANCOVAs (discounting and demand).

\begin{tabular}{lccc|cccc|ccc|c}
\hline & \multicolumn{2}{c}{$\begin{array}{c}\text { Self-Control } \\
\text { Depletion }\end{array}$} & \multicolumn{3}{c}{$\begin{array}{c}\text { Nicotine } \\
\text { Deprivation }\end{array}$} & \multicolumn{5}{c}{ Interaction } \\
\cline { 2 - 9 } & $F$ & $p$ & $\eta^{2}$ & $F$ & $p$ & $\eta^{2}$ & $F$ & $p$ & $\eta^{2}$ & $N$ \\
\hline Craving & 0.18 & 0.67 & 0.00 & 15.73 & $<.01$ & 0.11 & 4.46 & 0.04 & 0.04 & 128 \\
Delay Discounting & 0.75 & 0.52 & 0.02 & 2.90 & 0.04 & 0.07 & 1.68 & 0.18 & 0.04 & 128 \\
Cigarette Demand & 1.14 & 0.34 & 0.05 & 2.06 & 0.08 & 0.08 & 0.89 & 0.49 & 0.04 & 128 \\
Latency to Smoke & 4.46 & 0.04 & 0.04 & 4.76 & 0.03 & 0.04 & 1.31 & 0.25 & 0.01 & 123 \\
\# Cigarettes Smoked & 0.18 & 0.67 & 0.00 & 1.45 & 0.23 & 0.01 & 0.07 & 0.79 & 0.00 & 120 \\
\hline
\end{tabular}


Craving. A main effect was observed for the deprivation manipulation $[F(1,122)=$ 15.73, $p<.01$, partial $\eta^{2}=.11$ ], but not for the SCD manipulation $(p=.67)$. As depicted in Figure 3, these manipulations interacted significantly, $F(1,122)=4.46, p=.04$, partial $\eta^{2}=.04$. This suggested that SCD depletion only increased self-reported craving when participants were in a state of nicotine deprivation. Indeed, follow up comparisons showed differential effect sizes of SCD when participants were deprived $\left[F(1,60)=40.40, p=.056\right.$, partial $\left.\eta^{2}=.06\right]$, relative to satiated $\left[F(1,59)=15.26, p=.29\right.$, partial $\left.\eta^{2}=.02\right]$. Furthermore, when tested against the complete control condition (no SCD + no deprivation), there was no effect of SCD (SCD + no deprivation, $p=.25$ ) or deprivation (no SCD + deprivation, $p=.23$ ) alone. Instead, these manipulations appeared to affect craving only when combined $[F(1,60)=10.01, p=.002$, partial $\left.\eta^{2}=.14\right]$

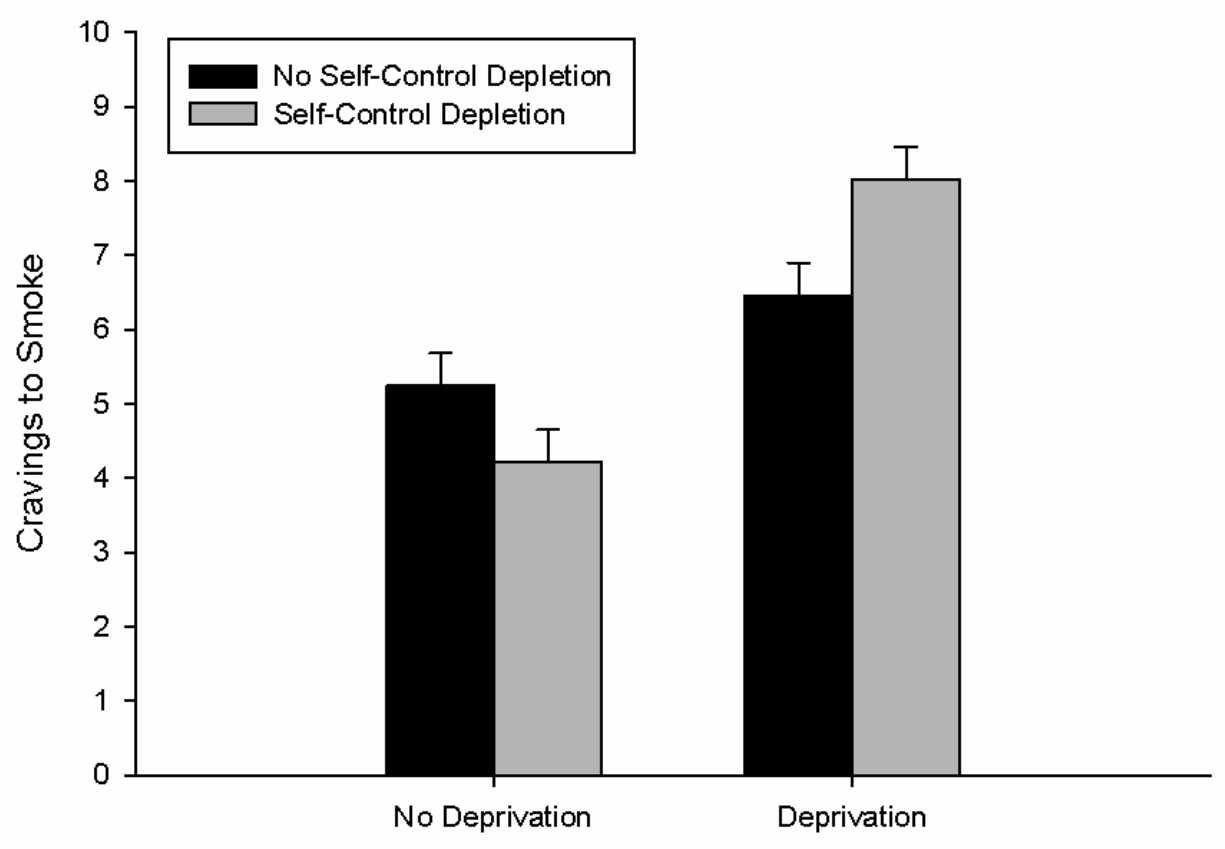

Figure 3. Mean composite craving ratings (and standard errors), as a function of the Self-Control Depletion manipulation x Nicotine Deprivation manipulation interaction $(p=.04)$. 
Delayed Reward Discounting. A non-significant Box’s M test $(p=.13)$ indicated homogeneity of covariance matrices; therefore we report Wilk's $\Lambda$ multivariate tests. The only significant multivariate main effect was due to the deprivation manipulation, $F(3,119)=$ 2.90, $p=.04$, partial $\eta^{2}=.07$. Follow up, univariate tests showed that this was driven by significant differences at the medium $\left[F(1,121)=4.84, p=.03\right.$, partial $\left.\eta^{2}=.04\right]$ and large reward magnitudes $\left[F(1,121)=4.31, p=.04\right.$, partial $\left.\eta^{2}=.03\right]$. Those deprived of nicotine discounted rewards to a greater degree than satiated participants for both medium $(M=.08 ; S E=$ .01 vs. $M=.06 ; S E=.01)$ and large reward magnitudes $(M=.07 ; S E=.01$ vs. $M=.04 ; S E=$ $.01)$.

Demand. A significant Box's M test $(\mathrm{p}=.01)$ indicated a lack of homogeneity of covariance matrices, therefore we report on Pillai's trace multivariate tests. The only multivariate main effect that approached significance was again a function of the deprivation manipulation, $F(5,118)=2.06, p=.076$, partial $\eta^{2}=.08$. Univariate tests showed that this was driven by significant differences for Omax, $F(1,122)=6.90, p=.01$, partial $\eta^{2}=.05$. Those deprived of nicotine had greater expenditure for cigarettes $(M=7.95$; $S E=.83)$, compared to those not deprived $(M=4.83 ; S E=.83)$.

Cessation Failure. As depicted in Figure 4, main effects were observed for both the SCD $\left[F(1,117)=4.46, p=.04\right.$, partial $\left.\eta^{2}=.04\right]$ and deprivation manipulations $[F(1,117)=4.76, p=$ .03 , partial $\left.\eta^{2}=.04\right]$ on latency to smoke. Although the SCD effect appear larger among those non-deprived, the interaction was not significant $(p=.26)$. Neither manipulation influenced cigarette consumption ( $p$ ’s $>.23$ ). That is, SCD and nicotine deprivation increased lapse behavior (i.e., decreased latency to smoke), but had negligible effects on relapse behavior (i.e., number of cigarettes smoked), within this laboratory analogue task. 


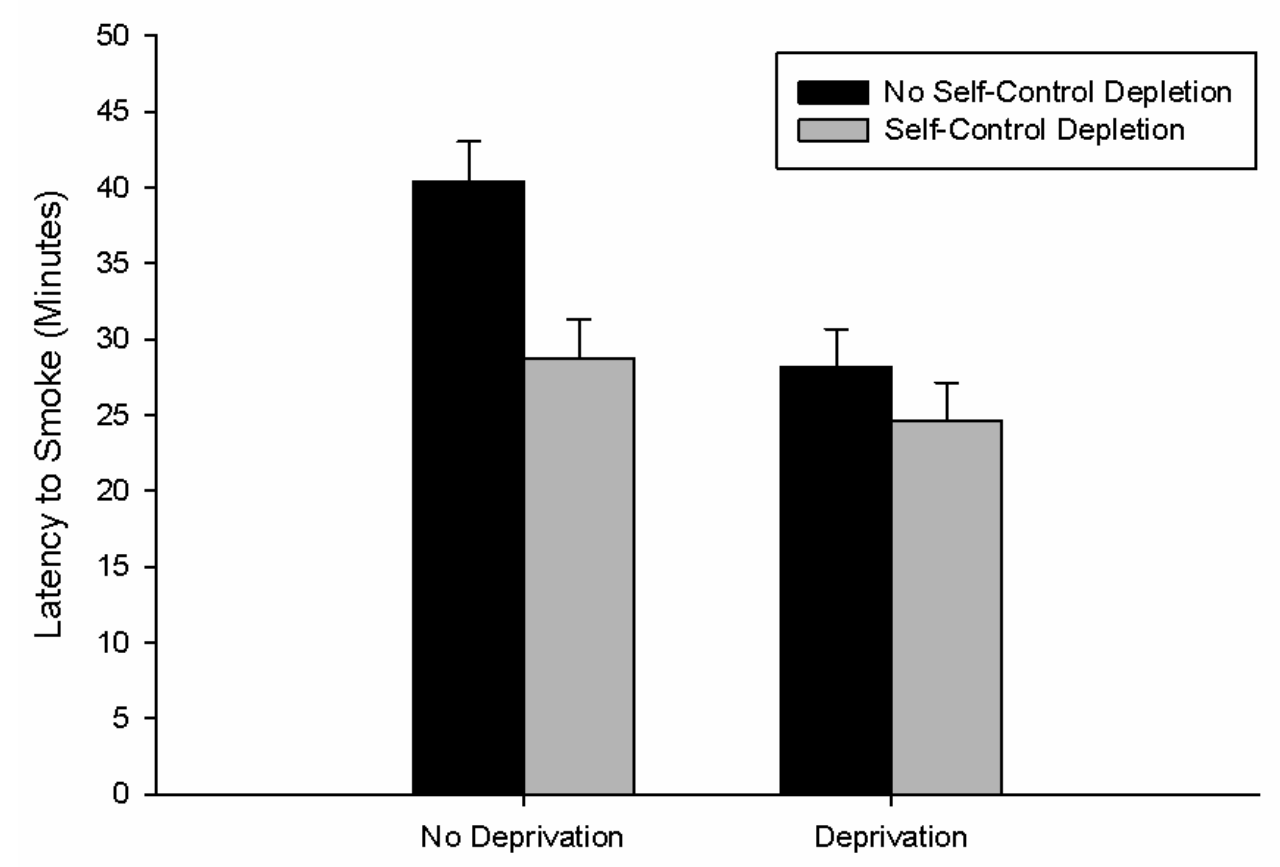

Figure 4. Latency to smoke (and standard errors), as a function of the Self-Control Depletion ( $p$ $=.04) \times$ Nicotine Deprivation manipulations $(p=.03)$.

\section{Mediation Analyses for Lapse Behavior}

To determine whether differences in smoking behavior produced by the experimental manipulations were indeed mediated by craving, discounting, and/or demand, bootstrap mediation analyses were conducted using PROCESS (Hayes, 2013). As recommended by Hayes (2013), data were resampled 5000 times (with replacement) and 95\% confidence intervals (bias corrected) were calculated. Putative mediators were considered statistically significant if their specific indirect effects had confidence intervals that did not include zero. Mediation model construction was conducted separately for the deprivation and SCD manipulations, and was informed by univariate results reported above such that mediators were included only if significant at the univariate level. 
Nicotine Deprivation Mediation Model. Given that craving, discounting (for medium and large rewards), and demand (Omax) were found to be significantly influenced by the deprivation manipulation at the univariate level, a parallel multiple mediation model tested independent and relative contribution of these variables (and controlled for SCD). The hypotheses that discounting and demand would mediate deprivation effects on latency to smoke were not observed. Mediation was only observed through craving (indirect point estimate = 3.19; $95 \% \mathrm{CI}=-7.32$ to -.64 ), such that increases in craving due to the deprivation manipulation led to decreased latency to smoke. Thus, craving was an important link between nicotine deprivation and latency to smoke, independent of SCD.

SCD Moderated Mediation Model. Craving was the only putative mediator found significant at the univariate level, but this was moderated by the nicotine deprivation manipulation. Therefore, we tested a moderated mediation model of SCD on latency to smoke, with deprivation status included as a moderator and craving as the sole mediator. Conditional effects found that mediation was observed among deprived participants (indirect point estimate $=$ $-2.44 ; 95 \% \mathrm{CI}=-6.05$ to -.18 ), but not in those non-deprived (indirect point estimate $=1.79$; $95 \% \mathrm{CI}=-.81$ to 5.54$)$. That is, increases in craving due to the SCD manipulation led to decreased latency to smoke, but only among participants in acute nicotine withdrawal. 


\section{Discussion}

\section{SCD as a Novel Cessation Failure Precipitant}

This is the first study, to our knowledge, to find that SCD may increase cravings to smoke, but we only found the effect among smokers deprived of nicotine. Furthermore, this effect mediated the observed increase in lapse behavior resultant from SCD during acute nicotine withdrawal. However, SCD did not influence the proposed behavioral economic mediators of delayed reward discounting and demand. Importantly, results provide causal evidence to suggest that SCD may be a novel precipitant for cessation failure through effects on time to lapse.

The validity of this conclusion is bolstered by the high degree of replication observed for nicotine deprivation effects across the various laboratory models of nicotine dependence tested here. Consistent with past research, we found acute abstinence to increase discounting, demand, craving, and cessation failure as indexed by latency to smoke (i.e., lapse). A unique finding was the relative importance of craving, as it was the only mediator for the relationship between our acute deprivation manipulation and lapse behavior.

\section{Theoretical Implications}

Interestingly, SCD increased lapse behavior for both deprived and satiated participants, but influenced craving only among deprived smokers. Thus, fluctuations of self-control resources appear to serve as an interoceptive cue to smoking behavior in general, but this may occur outside of awareness among those free of nicotine withdrawal. In light of evidence that smoking can restore depleted self-control (Heckman et al., 2012), smoking may be viewed as an 
automatic form of self-regulation that does not require deliberate control (Tiffany, 1990). Thus, frequent smoking may prevent SCD, thereby alleviating any subjective awareness for the need to smoke, which parallels negative reinforcement models of addiction that posit that consistent smoking may prevent negative affect from reaching consciousness (Baker, Piper, McCarthy, Majeskie, \& Fiore, 2004). However, when self-control resources are progressively taxed through competing demands, the need for self-control restoration may manifest through goal-directed conscious processes such as craving. Resources are likely to be greatly compromised during a quit attempt when smokers must cope with nicotine withdrawal (Bernstein, Trafton, Ilgen, \& Zvolensky, 2008). Thus, self-control strength may influence the act of smoking, but the extent to which SCD influences subjective motivational processes may depend on the magnitude of SCD, based on factors such as nicotine deprivation or negative affect (Heckman et al., 2013).

Although both experimental manipulations increased cessation failure, they differentially impacted behavioral economic indices (i.e., discounting and demand). That SCD did not affect impulsive decision making (i.e., discounting) suggests that self-control and impulsivity may not serve as antipodes on a self-control/impulsivity continuum (Bickel, Jarmolowicz, Mueller, Gatchalian, \& McClure, 2012), as suggested by proponents of the Self-Control Strength Model (Tice et al., 2001). Instead, data converged with the Competing Neurobehavioral Decision Systems Theory (Bickel et al., 2011; Bickel et al., 2007), which proposes that addictive behaviors are regulated by the relative strength of two systems. The impulsive system is driven primarily by limbic and paralimbic areas, and prefrontal cortices allow for top-down control via the executive system (McClure, Laibson, Loewenstein, \& Cohen, 2004). According to this theory, the current study manipulated the executive system through the SCD manipulation (Heatherton, 2011; Heatherton \& Wagner, 2011), and the impulsive system through the 
deprivation manipulation (Bickel et al., 2011). As such, our findings replicate the suggestion that the impulsive system is critical when it comes to the choice of immediate reinforcers (Bickel, Pitcock, Yi, \& Angtuaco, 2009). However, nicotine deprivation may have also influenced the executive system (Ashare, Falcone, \& Lerman, 2014). The functional connectivity of neural systems is only beginning to be understood through resource allocation models, and acute nicotine deprivation has been found to disrupt inter-network connectivity in a manner that promotes craving and cognitive performance deficits (Lerman et al., 2014; Sutherland, McHugh, Pariyadath, \& Stein, 2012). Large-scale brain networks methodology could also be applied to elucidate the pathophysiological underpinnings of cessation failure through SCD.

Characterization of biological mechanisms through which SCD acts would address a major shortcoming of the Self-Control Strength Model (Inzlicht et al., 2014; Robinson et al., 2010), as a direct index of SCD (other than behavioral expression) has yet to be identified.

\section{Limitations}

In addition to potential limitations of the theories that inspired the current study and the measurement of relevant constructs, there are study specific-limitations worth noting. For example, the current study may be susceptive to Type I error given the number of analyses conducted without formal correction of statistical significance. However, we chose this approach because our primary aim was to test the influence of SCD on cessation failure (only two analyses) and putative mediators (only three analyses), and deprivation analyses replicated previous studies. Additionally, the between-subject design used here may have influenced sample characteristics across the study conditions. Although all conditions were equivalent across demographic and some smoking-related variables (e.g., cigarettes per day, motivation to quit), there were differences in nicotine dependence and self-efficacy between the deprivation 
and no deprivation conditions. Given that those deprived had to sustain 12 hours of abstinence, it is likely that those more dependent or unable to quit for 12 hours may have been underrepresented in the deprivation conditions. Craving, demand, and cessation failure are positively associated with nicotine dependence, which suggests that our findings may underestimate effect sizes observed across deprivation analyses. This was controlled for statistically in the current study, but future studies may mitigate this concern through withinsubject designs.

Finally, interpretation of study findings should, of course, be tempered by the extent to which the laboratory tasks model naturalistic cessation failure. Although we selected assessments that have previously been found to predict cessation failure and relapse precipitants found in treatment outcome studies, our sample consisted of smokers not attempting to quit. Thus, our approach traded off external validity in order to provide the most stringent and internally valid test of whether, and through what mechanisms, SCD may serve as an antecedent to cessation failure. A logical next step would be to test this in the real world, which could be accomplished using ecological momentary assessment (Hofmann, Baumeister, Forster, \& Vohs, 2012). Using this methodology, self-control demands have been found to predict alcohol consumption (Muraven, Collins, Shiffman, \& Paty, 2005). Although studies have tested the effects of resisting temptations to smoke on cessation failure (O'Connell, Schwartz, \& Shiffman, 2008), the role of self-control demands non-specific to substance use have yet to be tested.

\section{Treatment Implications}

Although resisting cravings have been found to deplete self-control resources (Hagger et al., 2013; Muraven \& Shmueli, 2006), SCD effects are also observed across affective and cognitive manipulations devoid of drug cues/craving, including: controlling emotion, thoughts, 
impulses and attention, choice and volition, cognitive processing, and social processing (Hagger et al., 2010). That is, self-control strength is theorized to be a domain-independent process, and subject to fatigue from a variety of sources (Baumeister et al., 2007). Given the multi-determined and dynamic nature of motivational factors that may underlie smoking, SCD may provide an integrative relapse precipitant that captures momentary fluctuations from all self-control demands. Should this be the case, the self-control strength literature provides insight into interventions that may enhance cessation success.

Analogous to increased muscle tone through weight lifting, nine studies have shown that regular exercise of self-control strengthens self-control reserves ( $d=1.07$; Hagger et al., 2010). Pre-cessation strength training may enhance the capacity to cope with withdrawal symptoms, cue-provoked cravings, and non-smoking self-control demands (e.g., stress) during a cessation attempt. A behavioral intervention as simple as having smokers engage in repeated acts of posture checking over two weeks led to increased abstinence duration (Muraven, 2010). Similar conceptually is cognitive remediation training, which is a promising candidate for reducing addictive behaviors (Bickel, Yi, Landes, Hill, \& Baxter, 2011). Importantly, self-control training interventions have high dissemination potential, as they can be delivered effectively through smartphones and the internet (Cranwell et al., 2014).

It is also imperative to address state dependent fluctuations of self-control strength, as smoking may be a key method to cope with SCD prior to cessation. Fortunately, many strategies have been found to counteract the detrimental effects of SCD, and therefore may serve as viable alternatives to smoking. Some can be taught pre-cessation and mirror traditional cognitive approaches, for example: implementation intentions (Webb \& Sheeran, 2002), self-awareness (Alberts, Martijn, \& de Vries, 2011), and self-affirmation (Schmeichel \& Vohs, 2009). 
Behavioral methods can be employed directly after SCD, and parallel contingency management interventions in that they provide rewards, such as: positive mood induction (Tice, Baumeister, Shmueli, \& Muraven, 2007), relaxation (Tyler \& Burns, 2008), glucose administration ( $d=.75, k$ = 5; Hagger et al., 2010), and monetary and social contingencies (Muraven \& Slessareva, 2003). It is unclear to what degree these acute SCD methods directly restore self-control resources, enhance motivation to use remaining self-control reserves, or act through other mechanisms (Beedie \& Lane, 2012; Inzlicht \& Schmeichel, 2013; Kurzban et al., 2013; Molden et al., 2012), but all have been found to nullify SCD effects within non-smokers. That these strategies are similar to those within current cognitive-behavioral smoking cessation interventions (Perkins, Conklin, \& Levine, 2008) infers strong potential for dissemination and implementation, should they be found effective within samples of smokers (Shmueli \& Prochaska, 2012). An important distinction, however, is that the specific target of these strategies would be SCD, rather than smoking per se.

The number and potential reach of self-control strength interventions is promising, yet only one study has applied self-control theory with respect to smoking cessation (Muraven, 2010). Furthermore, no study has tested the utility of combining trait and state self-control interventions, or more than one state intervention simultaneously. The laboratory paradigm employed here could be used to screen self-control interventions prior to full scale clinical trials, just as it has been used for pharmacotherapy screening (McKee et al., 2012). Identification of effective self-control interventions may provide benefits beyond smoking cessation, as numerous behavioral and impulse-control problems have been linked to self-control failure, including: overeating, alcohol and drug abuse, crime and violence, overspending, sexually impulsive behavior, and gambling (Baumeister, Heatherton, \& Tice, 1994) 


\section{Conclusion}

We provided causal evidence via lapse behavior in a laboratory analogue task to suggest that SCD is a novel antecedent to cessation failure. We also found that this effect may occur outside of awareness among minimally deprived smokers, serving as an automatic form of selfregulation. However, among nicotine-deprived smokers (simulating a quit attempt) craving mediates the relationship between SCD and cessation failure. Thus, the current study suggests that SCD is involved in the maintenance of nicotine dependence, and provided a theoretical framework for how it influences behavior. 


\section{References}

Acker, J., \& MacKillop, J. (2013). Behavioral economic analysis of cue-elicited craving for tobacco: a virtual reality study. Nicotine \& Tobacco Research, 15, 1409-1416.

Alberts, H. J. E. M., Martijn, C., \& de Vries, N. K. (2011). Fighting self-control failure: Overcoming ego depletion by increasing self-awareness. Journal of Experimental Social Psychology, 47, 58-62.

Ashare, R. L., Falcone, M., \& Lerman, C. (2014). Cognitive function during nicotine withdrawal: Implications for nicotine dependence treatment. Neuropharmacology, 76, 581-591.

Ashare, R. L., \& Hawk, L. W., Jr. (2012). Effects of smoking abstinence on impulsive behavior among smokers high and low in ADHD-like symptoms. Psychopharmacology, 219, 537547.

American Psychiatric Association (APA) (1994). Diagnostic and statistical manual of mental disorders (4th ed.). Washington, DC: American Psychiatric Publishing.

American Psychiatric Association (APA) (2013). Diagnostic and statistical manual of mental disorders (5th ed.). Arlington, VA: American Psychiatric Publishing.

Baker, T. B., Breslau, N., Covey, L., \& Shiffman, S. (2012). DSM criteria for tobacco use disorder and tobacco withdrawal: A critique and proposed revisions for DSM-5. Addiction, 107, 263-275. 
Baker, T. B., Piper, M. E., McCarthy, D. E., Majeskie, M. R., \& Fiore, M. C. (2004). Addiction motivation reformulated: An affective processing model of negative reinforcement. Psychological Review, 111, 33-51.

Baumeister, R. F., Bratslavsky, E., Muraven, M., \& Tice, D. M. (1998). Ego depletion: is the active self a limited resource? Journal of Personality and Social Psychology, 74, 12521265.

Baumeister, R. F., Heatherton, T. F., \& Tice, D. M. (1994). Losing control: How and why people fail at self-regulation. San Diego, CA: Academic Press.

Baumeister, R. F., Vohs, K. D., \& Tice, D. M. (2007). The strength model of self-control. Current Directions in Psychological Science, 16, 351-355.

Beedie, C. J., \& Lane, A. M. (2012). The role of glucose in self-control: Another look at the evidence and an alternative conceptualization. Personality and Social Psychology Review, 16, 143-153.

Bernstein, A., Trafton, J., Ilgen, M., \& Zvolensky, M. J. (2008). An evaluation of the role of smoking context on a biobehavioral index of distress tolerance. Addictive Behaviors, 33, 1409-1415.

Bickel, W. K., Jarmolowicz, D. P., Mueller, E. T., \& Gatchalian, K. M. (2011). The behavioral economics and neuroeconomics of reinforcer pathologies:Implications for etiology and treatment of addiction. Current Psychiatry Reports, 13, 406-415.

Bickel, W. K., Jarmolowicz, D. P., Mueller, E. T., Gatchalian, K. M., \& McClure, S. M. (2012). Are executive function and impulsivity antipodes? A conceptual reconstruction with special reference to addiction. Psychopharmacology, 221, 361-387. 
Bickel, W. K., Koffarnus, M. N., Moody, L., \& Wilson, A. G. (2014). The behavioral- and neuro-economic process of temporal discounting: A candidate behavioral marker of addiction. Neuropharmacology, 76, 518-527.

Bickel, W. K., Miller, M. L., Yi, R., Kowal, B. P., Lindquist, D. M., \& Pitcock, J. A. (2007). Behavioral and neuroeconomics of drug addiction: Competing neural systems and temporal discounting processes. Drug and Alcohol Dependence, 90, S85-91.

Bickel, W. K., Pitcock, J. A., Yi, R., \& Angtuaco, E. J. (2009). Congruence of BOLD response across intertemporal choice conditions: Fictive and real money gains and losses. The Journal of Neuroscience, 29, 8839-8846.

Bickel, W. K., Yi, R., Landes, R. D., Hill, P. F., \& Baxter, C. (2011). Remember the future: Working memory training decreases delay discounting among stimulant addicts. Biological Psychiatry, 69, 260-265.

Biener, L., \& Abrams, D. B. (1991). The Contemplation Ladder: Validation of a measure of readiness to consider smoking cessation. Health Psychology, 10, 360-365.

Brandon, T. H., Tiffany, S. T., Obremski, K. M., \& Baker, T. B. (1990). Postcessation cigarette use: the process of relapse. Addictive Behaviors, 15, 105-114.

Center for Disease Control and Prevention (CDCP) (2011). Quitting smoking among adults-United States, 2001-2010. Morbidity and Mortality Weekly Report, 60, 1513-1519.

Christiansen, P., Cole, J. C., \& Field, M. (2012). Ego depletion increases ad-lib alcohol consumption: investigating cognitive mediators and moderators. Experimental and Clinical Psychopharmacology, 20, 118-128.

Cohen, J. (1988). Statistical power analysis for the behavioral sciences (2nd ed.). Hillsdale, NJ: Erlbaum Associates. 
Cranwell, J., Benford, S., Houghton, R. J., Golembewksi, M., Fischer, J. E., \& Hagger, M. S. (2014). Increasing self-regulatory energy using an internet-based training application delivered by smartphone technology. Cyberpsycholoby, Behavior, and Social Networking, 17, 181-186.

Diener, E., \& Emmons, R. A. (1984). The independence of positive and negative affect. Journal of Personality and Social Psychology, 47, 1105-1117.

Etter, J. F., \& Hughes, J. R. (2006). A comparison of the psychometric properties of three cigarette withdrawal scales. Addiction, 101, 362-372.

Field, M., Santarcangelo, M., Sumnall, H., Goudie, A., \& Cole, J. (2006). Delay discounting and the behavioural economics of cigarette purchases in smokers: The effects of nicotine deprivation. Psychopharmacology, 186, 255-263.

Gailliot, M. T., Baumeister, R. F., DeWall, C. N., Maner, J. K., Plant, E. A., Tice, D. M., .. . Schmeichel, B. J. (2007). Self-control relies on glucose as a limited energy source: Willpower is more than a metaphor. Journal of Personality and Social Psychology, 92, 325-336.

Garvey, A. J., Bliss, R. E., Hitchcock, J. L., Heinold, J. W., \& Rosner, B. (1992). Predictors of smoking relapse among self-quitters: A report from the Normative Aging Study. Addictive Behaviors, 17, 367-377.

Gilbert, D. G., McClernon, F. J., Rabinovich, N. E., Plath, L. C., Masson, C. L., Anderson, A. E., \& Sly, K. F. (2002). Mood disturbance fails to resolve across 31 days of cigarette abstinence in women. Journal of Consulting and Clinical Psychology, 70, 142-152. 
Gross, J. J. (1998). Antecedent- and response-focused emotion regulation: Divergent consequences for experience, expression, and physiology. Journal of Personality and Social Psychology, 74, 224-237.

Hagger, M. S., Leaver, E., Esser, K., Leung, C. M., Te Pas, N., Keatley, D. A., . . .

Chatzisarantis, N. L. (2013). Cue-induced smoking urges deplete cigarette smokers' selfcontrol resources. Annals of Behavioral Medicine, 46, 394-400.

Hagger, M. S., Wood, C., Stiff, C., \& Chatzisarantis, N. L. (2010). Ego depletion and the strength model of self-control: A meta-analysis. Psychological Bulletin, 136, 495-525.

Hayes, A. F. (2013). Introduction to mediation, moderation, and conditional process analysis: A regression-based approach. New York, NY: Guilford Press.

Heatherton, T. F. (2011). Neuroscience of self and self-regulation. Annual Review of Psychology, 62, 363-390.

Heatherton, T. F., Kozlowski, L. T., Frecker, R. C., \& Fagerstrom, K. O. (1991). The Fagerstrom test for nicotine dependence: A revision of the Fagerstrom tolerance questionnaire. British Journal of Addiction, 86, 1119-1127.

Heatherton, T. F., \& Wagner, D. D. (2011). Cognitive neuroscience of self-regulation failure. Trends in Cognitive Sciences, 15, 132-139.

Heckman, B. W., Ditre, J. W., \& Brandon, T. H. (2012). The restorative effects of smoking upon self-control resources: A negative reinforcement pathway. Journal of Abnormal Psychology, 121, 244-249.

Heckman, B. W., Kovacs, M. A., Marquinez, N. S., Meltzer, L. R., Tsambarlis, M. E., Drobes, D. J., \& Brandon, T. H. (2013). Influence of affective manipulations on cigarette craving: A meta-analysis. Addiction, 108, 2068-2078. 
Heishman, S. J., Singleton, E. G., \& Pickworth, W. B. (2008). Reliability and validity of a Short Form of the Tobacco Craving Questionnaire. Nicotine \& Tobacco Research, 10, 643-651. Hendricks, P. S., Delucchi, K. L., Benowitz, N. L., \& Hall, S. M. (2014). Clinical significance of early smoking withdrawal effects and their relationships with nicotine metabolism: Preliminary results from a pilot study. Nicotine \& Tobacco Research, 16, 615-620.

Hendricks, P. S., Ditre, J. W., Drobes, D. J., \& Brandon, T. H. (2006). The early time course of smoking withdrawal effects. Psychopharmacology, 187, 385-396.

Hofmann, W., Baumeister, R. F., Forster, G., \& Vohs, K. D. (2012). Everyday temptations: An experience sampling study of desire, conflict, and self-control. Journal of Personality and Social Psychology, 102, 1318-1335.

Hughes, J. R. (1992). Tobacco withdrawal in self-quitters. Journal of Consulting and Clinical Psychology, 60, 689-697.

Hughes, J. R. (2007a). Effects of abstinence from tobacco: Etiology, animal models, epidemiology, and significance: A subjective review. Nicotine \& Tobacco Research, 9, 329-339.

Hughes, J. R. (2007b). Effects of abstinence from tobacco: Valid symptoms and time course. Nicotine \& Tobacco Research, 9, 315-327.

Hughes, J. R. (2007c). Measurement of the effects of abstinence from tobacco: a qualitative review. Psychology of Addictive Behaviors, 21, 127-137.

Hughes, J. R., \& Hatsukami, D. (1986). Signs and symptoms of tobacco withdrawal. Archives of General Psychiatry, 43, 289-294.

Hursh, S. R., \& Silberberg, A. (2008). Economic demand and essential value. Psychological Review, 115, 186-198. 
Inzlicht, M., \& Schmeichel, B. J. (2013). Beyond simple utility in predicting self-control fatigue: A proximate alternative to the opportunity cost model. Behavioral and Brain Sciences, 36, 695-696; discussion 707-626.

Inzlicht, M., Schmeichel, B. J., \& Macrae, C. N. (2014). Why self-control seems (but may not be) limited. Trends in Cognitive Sciences, 18, 127-133.

Kahler, C. W., Brown, R. A., Ramsey, S. E., Niaura, R., Abrams, D. B., Goldstein, M. G., . . . Miller, I. W. (2002). Negative mood, depressive symptoms, and major depression after smoking cessation treatment in smokers with a history of major depressive disorder. Journal of Abnormal Psychology, 111, 670-675.

Kenford, S. L., Fiore, M. C., Jorenby, D. E., Smith, S. S., Wetter, D., \& Baker, T. B. (1994). Predicting smoking cessation. Who will quit with and without the nicotine patch. JAMA, 271, 589-594.

Kenford, S. L., Smith, S. S., Wetter, D. W., Jorenby, D. E., Fiore, M. C., \& Baker, T. B. (2002). Predicting relapse back to smoking: Contrasting affective and physical models of dependence. Journal of Consulting and Clinical Psychology, 70, 216-227.

Kirby, K. N., Petry, N. M., \& Bickel, W. K. (1999). Heroin addicts discount delayed rewards at higher rates than non-drug using controls. Journal of Experimental Psychology: General, $128,78-87$.

Kirchner, T. R., Cantrell, J., Anesetti-Rothermel, A., Ganz, O., Vallone, D. M., \& Abrams, D. B. (2013). Geospatial exposure to point-of-sale tobacco: Real-time craving and smokingcessation outcomes. American Journal of Preventitive Medicine, 45, 379-385. 
Koffarnus, M. N., Jarmolowicz, D. P., Mueller, E. T., \& Bickel, W. K. (2013). Changing delay discounting in the light of the competing neurobehavioral decision systems theory: A review. Journal of the Experimental Analysis of Behavior, 99, 32-57.

Kurzban, R., Duckworth, A., Kable, J. W., \& Myers, J. (2013). An opportunity cost model of subjective effort and task performance. Behavioral and Brain Sciences, 36, 661-679.

Lagorio, C. H., \& Madden, G. J. (2005). Delay discounting of real and hypothetical rewards III: Steady-state assessments, forced-choice trials, and all real rewards. Behavioural Processes, 69, 173-187.

Laibson, D. I. (2001). A cue-theory of consumption. Quarterly Journal of Economics, 116, 81119.

Leeman, R. F., O’Malley, S. S., White, M. A., \& McKee, S. A. (2010). Nicotine and food deprivation decrease the ability to resist smoking. Psychopharmacology, 212, 25-32.

Lerman, C., Gu, H., Loughead, J., Ruparel, K., Yang, Y., \& Stein, E. A. (in press). Large-scale brain network coupling predicts acute nicotine abstinence effects on craving and cognitive function. JAMA Psychiatry.

Lerman, C., LeSage, M. G., Perkins, K. A., O'Malley, S. S., Siegel, S. J., Benowitz, N. L., \& Corrigall, W. A. (2007). Translational research in medication development for nicotine dependence. Nature Reviews Drug Discovery, 6, 746-762.

Leventhal, A. M., Waters, A. J., Moolchan, E. T., Heishman, S. J., \& Pickworth, W. B. (2010). A quantitative analysis of subjective, cognitive, and physiological manifestations of the acute tobacco abstinence syndrome. Addictive Behaviors, 35, 1120-1130. 
MacKillop, J., Amlung, M. T., Few, L. R., Ray, L. A., Sweet, L. H., \& Munafo, M. R. (2011). Delayed reward discounting and addictive behavior: A meta-analysis. Psychopharmacology, 216, 305-321.

MacKillop, J., Brown, C. L., Stojek, M. K., Murphy, C. M., Sweet, L., \& Niaura, R. S. (2012). Behavioral economic analysis of withdrawal- and cue-elicited craving for tobacco: An initial investigation. Nicotine \& Tobacco Research, 14, 1426-1434.

MacKillop, J., \& Kahler, C. W. (2009). Delayed reward discounting predicts treatment response for heavy drinkers receiving smoking cessation treatment. Drug and Alcohol Dependence, 104, 197-203.

MacKillop, J., Miranda, R., Monti, P. M., Ray, L. A., Murphy, J. G., Rohsenow, D. J., . . . Gwaltney, C. J. (2010). Alcohol demand, delayed reward discounting, and craving in relation to drinking and alcohol use disorders. Journal of Abnormal Psychology, 119, 106-114.

MacKillop, J., \& Murphy, J. G. (2007). A behavioral economic measure of demand for alcohol predicts brief intervention outcomes. Drug and Alcohol Dependence, 89, 227-233.

MacKillop, J., Murphy, J. G., Ray, L. A., Eisenberg, D. T. A., Lisman, S. A., Lum, J. K., \& Wilson, D. S. (2008). Further validation of a cigarette purchase task for assessing the relative reinforcing efficacy of nicotine in college smokers. Experimental and Clinical Psychopharmacology, 16, 57-65.

MacKillop, J., Murphy, J. G., Tidey, J. W., Kahler, C. W., Ray, L. A., \& Bickel, W. K. (2009). Latent structure of facets of alcohol reinforcement from a behavioral economic demand curve. Psychopharmacology, 203, 33-40. 
MacKillop, J., O'Hagen, S., Lisman, S. A., Murphy, J. G., Ray, L. A., Tidey, J. W., . . Monti, P. M. (2010). Behavioral economic analysis of cue-elicited craving for alcohol. Addiction, 105, 1599-1607.

Madden, G. J., Begotka, A. M., Raiff, B. R., \& Kastern, L. L. (2003). Delay discounting of real and hypothetical rewards. Experimental and Clinical Psychopharmacology, 11, 139-145.

Madden, G. J., \& Bickel, W. K. (2009). Impulsivity: The behavioral and neurological science of discounting. Washington, DC: American Psychological Association.

Madden, G. J., Raiff, B. R., Lagorio, C. H., Begotka, A. M., Mueller, A. M., Hehli, D. J., \& Wegener, A. A. (2004). Delay discounting of potentially real and hypothetical rewards: II. Between- and within-subject comparisons. Experimental and Clinical Psychopharmacology, 12, 251-261.

McCarthy, D. E., Piasecki, T. M., Fiore, M. C., \& Baker, T. B. (2006). Life before and after quitting smoking: An electronic diary study. Journal of Abnormal Psychology, 115, 454466.

McClure, S. M., Laibson, D. I., Loewenstein, G., \& Cohen, J. D. (2004). Separate neural systems value immediate and delayed monetary rewards. Science, 306, 503-507.

McKee, S. A. (2009). Developing human laboratory models of smoking lapse behavior for medication screening. Addiction Biology, 14, 99-107.

McKee, S. A., Krishnan-Sarin, S., Shi, J., Mase, T., \& O’Malley, S. S. (2006). Modeling the effect of alcohol on smoking lapse behavior. Psychopharmacology, 189, 201-210.

McKee, S. A., Sinha, R., Weinberger, A. H., Sofuoglu, M., Harrison, E. L., Lavery, M., \& Wanzer, J. (2010). Stress decreases the ability to resist smoking and potentiates smoking intensity and reward. Journal of Psychopharmacology, 25, 490-502. 
McKee, S. A., Weinberger, A. H., Shi, J., Tetrault, J., \& Coppola, S. (2012). Developing and validating a human laboratory model to screen medications for smoking cessation. Nicotine \& Tobacco Research, 14, 1362-1371.

Mitchell, S. H. (2004). Effects of short-term nicotine deprivation on decision-making: Delay, uncertainty, and effort discounting. Nicotine \& Tobacco Research, 6, 819-828.

Molden, D. C., Hui, C. M., Scholer, A. A., Meier, B. P., Noreen, E. E., D'Agostino, P. R., \& Martin, V. (2012). Motivational versus metabolic effects of carbohydrates on self-control. Psychol Sci, 23, 1137-1144.

Muraven, M. (2010). Practicing self-control lowers the risk of smoking lapse. Psycholology of Addictive Behaviors, 24, 446-452.

Muraven, M., Collins, R. L., Shiffman, S., \& Paty, J. A. (2005). Daily fluctuations in self-control demands and alcohol intake. Psychology of Addictive Behaviors, 19, 140-147.

Muraven, M., \& Shmueli, D. (2006). The self-control costs of fighting the temptation to drink. Psychology of Addictive Behaviors, 20, 154-160.

Muraven, M., \& Slessareva, E. (2003). Mechanism of self-control failure: Motivation and limited resources. Personality and Social Psychology Bulletin, 29, 894-906.

Murphy, J. G., \& MacKillop, J. (2006). Relative reinforcing efficacy of alcohol among college student drinkers. Experimental and Clinical Psychopharmacology, 14, 219-227.

Murphy, J. G., MacKillop, J., Skidmore, J. R., \& Pederson, A. A. (2009). Reliability and validity of a demand curve measure of alcohol reinforcement. Experimental and Clinical Psychopharmacology, 17, 396-404. 
Murphy, J. G., MacKillop, J., Tidey, J. W., Brazil, L. A., \& Colby, S. M. (2011). Validity of a demand curve measure of nicotine reinforcement with adolescent smokers. Drug and Alcohol Dependence, 113, 207-214.

O'Connell, K. A., Schwartz, J. E., \& Shiffman, S. (2008). Do resisted temptations during smoking cessation deplete or augment self-control resources? Psychology of Addictive Behaviors, 22, 486-495.

Paulhus, D. L. (1991). Measurement and control of response bias. In J. P. Robinson, P. R. Shaver, \& L. S. Wrightsman (Eds.), Measures of personality and social psychological attitudes (pp. 17-59). San Diego, CA: Academic Press.

Perkins, K., Stitzer, M., \& Lerman, C. (2006). Medication screening for smoking cessation: A proposal for new methodologies. Psychopharmacology, 184, 628-636.

Perkins, K. A., Conklin, C. A., \& Levine, M. D. (2008). Cognitive-behavioral therapy for smoking cessation: A practical guidebook to the most effective treatments. New York, NY: Taylor \& Francis.

Perkins, K. A., \& Lerman, C. (2014). An efficient early phase 2 procedure to screen medications for efficacy in smoking cessation. Psychopharmacology, 231, 1-11.

Perkins, K. A., Lerman, C., Fonte, C. A., Mercincavage, M., Stitzer, M. L., Chengappa, K. N., \& Jain, A. (2010). Cross-validation of a new procedure for early screening of smoking cessation medications in humans. Clinical Pharmacology \& Therapeutics, 88, 109-114.

Perkins, K. A., Lerman, C., Karelitz, J. L., Jao, N. C., Chengappa, K. N., \& Sparks, G. M. (2013). Sensitivity and specificity of a procedure for early human screening of novel smoking cessation medications. Addiction, 108, 1962-1968. 
Perkins, K. A., Lerman, C., Stitzer, M., Fonte, C. A., Briski, J. L., Scott, J. A., \& Chengappa, K. N. (2008). Development of procedures for early screening of smoking cessation medications in humans. Clinical Pharmacology \& Therapeutics, 84, 216-221.

Piasecki, T. M., Fiore, M. C., \& Baker, T. B. (1998). Profiles in discouragement: two studies of variability in the time course of smoking withdrawal symptoms. Journal of Abnormal Psychology, 107, 238-251.

Piasecki, T. M., Jorenby, D. E., Smith, S. S., Fiore, M. C., \& Baker, T. B. (2003a). Smoking withdrawal dynamics: III. Correlates of withdrawal heterogeneity. Experimental and Clinical Psychopharmacology, 11, 276-285.

Piasecki, T. M., Jorenby, D. E., Smith, S. S., Fiore, M. C., \& Baker, T. B. (2003b). Smoking withdrawal dynamics: I. Abstinence distress in lapsers and abstainers. Journal of Abnormal Psychology, 112, 3-13.

Piasecki, T. M., Jorenby, D. E., Smith, S. S., Fiore, M. C., \& Baker, T. B. (2003c). Smoking withdrawal dynamics: II. Improved tests of withdrawal-relapse relations. Journal of Abnormal Psychology, 112, 14-27.

Piasecki, T. M., Niaura, R., Shadel, W. G., Abrams, D., Goldstein, M., Fiore, M. C., \& Baker, T. B. (2000). Smoking withdrawal dynamics in unaided quitters. Journal of Abnormal Psychology, 109, 74-86.

Piper, M. E., Federmen, E. B., McCarthy, D. E., Bolt, D. M., Smith, S. S., Fiore, M. C., \& Baker, T. B. (2008). Using mediational models to explore the nature of tobacco motivation and tobacco treatment effects. Journal of Abnormal Psychology, 117, 94-105. 
Piper, M. E., Schlam, T. R., Cook, J. W., Sheffer, M. A., Smith, S. S., Loh, W. Y., .. . Baker, T. B. (2011). Tobacco withdrawal components and their relations with cessation success. Psychopharmacology, 216, 569-578.

Robinson, M. D., Schmeichel, B. J., \& Inzlicht, M. (2010). A cognitive control perspective of self-control strength and its depletion. Social and Personality Psychology Compass, 4, 189-200.

Roche, D. J., Bujarski, S., Moallem, N. R., Guzman, I., Shapiro, J. R., \& Ray, L. A. (in press). Predictors of smoking lapse in a human laboratory paradigm. Psychopharmacology.

Sayers, W. M., \& Sayette, M. A. (2013). Suppression on your own terms: Internally generated displays of craving suppression predict rebound effects. Psychological Science, 24, 17401746.

Sayette, M. A., Martin, C. S., Hull, J. G., Wertz, J. M., \& Perrott, M. A. (2003). Effects of nicotine deprivation on craving response covariation in smokers. Journal of Abnormal Psychology, 112, 110-118.

Sayette, M. A., Martin, C. S., Wertz, J. M., Shiffman, S., \& Perrott, M. A. (2001). A multidimensional analysis of cue-elicited craving in heavy smokers and tobacco chippers. Addiction, 96, 1419-1432.

Schmeichel, B. J., \& Vohs, K. (2009). Self-affirmation and self-control: Affirming core values counteracts ego depletion. Journal of Personality and Social Psychology, 96, 770-782.

Shiffman, S. (1982). Relapse following smoking cessation: A situational analysis. Journal of Consulting and Clinical Psychology, 50, 71-86.

Shiffman, S. (1986). A cluster-analytic classification of smoking relapse episodes. Addictive Behaviors, 11, 295-307. 
Shiffman, S. (2009). Ecological momentary assessment (EMA) in studies of substance use. Psychological Assessment, 21, 486-497.

Shiffman, S., West, R., \& Gilbert, D. (2004). Recommendation for the assessment of tobacco craving and withdrawal in smoking cessation trials. Nicotine \& Tobacco Research, 6, 599-614.

Shiffman, S. M., \& Jarvik, M. E. (1976). Smoking withdrawal symptoms in two weeks of abstinence. Psychopharmacology, 50, 35-39.

Shmueli, D., \& Prochaska, J. J. (2009). Resisting tempting foods and smoking behavior: implications from a self-control theory perspective. Health Psychology, 28, 300-306.

Shmueli, D., \& Prochaska, J. J. (2012). A test of positive affect induction for countering selfcontrol depletion in cigarette smokers. Psychology of Addictive Behaviors, 26, 157-161.

Strong, D. R., Kahler, C. W., Leventhal, A. M., Abrantes, A. M., Lloyd-Richardson, E., Niaura, R., \& Brown, R. A. (2009). Impact of bupropion and cognitive-behavioral treatment for depression on positive affect, negative affect, and urges to smoke during cessation treatment. Nicotine \& Tobacco Research, 11, 1142-1153.

Sutherland, M. T., McHugh, M. J., Pariyadath, V., \& Stein, E. A. (2012). Resting state functional connectivity in addiction: Lessons learned and a road ahead. Neuroimage, 62, 2281-2295.

Swan, G. E., Ward, M. M., \& Jack, L. M. (1996). Abstinence effects as predictors of 28-day relapse in smokers. Addictive Behaviors, 21, 481-490.

Tabachnick, B. G., \& Fidell, L. S. (2013). Using multivariate statistics (6th ed.). Boston, MA: Pearson Education. 
Tice, D. M., Baumeister, R. F., Shmueli, D., \& Muraven, M. (2007). Restoring the self: Positive affect helps improve self-regulation following ego depletion. Journal of Experimental Social Psychology, 43, 379-384.

Tice, D. M., Bratslavsky, E., \& Baumeister, R. F. (2001). Emotional distress regulation takes precedence over impulse control: If you feel bad, do it! Journal of Personality and Social Psychology, 80, 53-67.

Tiffany, S. T. (1990). A cognitive model of drug urges and drug-use behavior: Role of automatic and nonautomatic processes. Psychological Review, 97, 147-168.

Tiffany, S. T., \& Wray, J. M. (2012). The clinical significance of drug craving. Annals of the New York Academy of Sciences, 1248, 1-17.

Tyler, J. M., \& Burns, K. C. (2008). After depletion: The replenishment of the self's regulatory resources. Self and Identity, 7, 305-321.

U.S. Department of Health and Human Services (USDHSS) (2014). The health consequences of smoking-50 years of Progress: A Report of the Surgeon General. Atlanta, GA: U.S. Department of Health and Human Services, Centers for Disease Control and Prevention, National Center for Chronic Disease Prevention and Health Promotion, Office on Smoking and Health.

Von Korff, M. (2011). Assessment of chronic pain in epidemiological and health services research: empirical bases and new directions. In T. C. T. R. Melzack (Ed.), Handbook of pain assessment (pp. 455-473). New York, NY: Guilford Press.

Webb, T. L., \& Sheeran, P. (2002). Can implementation intentions help to overcome egodepletion? Journal of Experimental Social Psychology, 39, 279-286. 
Westman, E. C., Behm, F. M., Simel, D. L., \& Rose, J. E. (1997). Smoking behavior on the first day of a quit attempt predicts long-term abstinence. Archives of Internal Medicine, 157, $335-340$.

Whiteside, S. P., \& Lynam, D. R. (2001). The Five Factor Model and impulsivity: Using a structural model of personality to understand impulsivity. Personality and Individual Differences, 30, 669-689.

World Health Organization (WHO) (2011). WHO report on the global tobacco epidemic: Warnings about the dangers of tobacco. Geneva, Switzerland: WHO Press. 